\title{
Experimental study of low-damage drilling fluid to minimize waterblocking of low-permeability gas reservoirs
}

\author{
Zhang Hongxia ${ }^{1}$, Yan Jienian ${ }^{1 *}$, Lu Yu ${ }^{2}$, Shu Yong ${ }^{1}$ and Zhao Shengying ${ }^{1}$ \\ ${ }^{1}$ Key Laboratory of Petroleum Engineering, Ministry of Education, China University of Petroleum, Beijing 102249, China \\ ${ }^{2}$ Drilling Fluid Branch, Great Wall Drilling Company, PetroChina, Panjin, Liaoning 124010, China
}

\begin{abstract}
This paper discusses the systematic design and development of low-damage drilling fluid to protect the low-permeability gas reservoir of the Sulige block in the Ordos Basin, Inner Mongolia Autonomous Region, China. Based on investigation of the geological characteristics and the potential formation damage of the Permian formation of the reservoir, waterblocking due to invasion of drilling or completion fluids was identified one of the most severe causes of damage to gas well deliverability. By adopting the phase trap prevention method, ideal packing theory, and film-forming technology, a lowdamage drilling fluid, sodium formate brine containing efficient waterblocking preventing surfactants, optimized temporary bridging agents (TBAs), and film-forming agents has been developed. The performance of the new drilling fluid was evaluated by using a variety of techniques. The results show that the fluid has good rheological properties, good strong shale-swelling inhibition, good temporary plugging effect, ultra-low filtration, and good lubricity. It can efficiently minimize waterblocking and can be used to drill horizontal wells with minimal intervention of the reservoir in the Sulige Gas Field.
\end{abstract}

Key words: Low-permeability gas reservoir, waterblocking, ideal packing theory (IPT), film-forming agent, drilling fluid

\section{Introduction}

Extensive reserves of natural gas are present worldwide in both sandstone and carbonate formations, which have low effective in-situ gas permeability. Numerous studies (Bennion et al, 1999, 2000b; Erwom et al, 2003; Lin et al, 2003; Ren et al, 2004) showed that waterblocking (phase trapping) caused by invading fluids during drilling and production operations, was one of the major mechanisms of productivity reduction. The extent of damage commonly ranged from $70 \%$ to $90 \%$. An excellent overview of diagnostic and remedial options to mitigate phase trapping issues was given by Bennion and Thomas (2005). Most of the published literature considered fracturing treatment or stimulations. They claimed that aqueous stimulation fluids containing alcohol had proved to be highly successful in stimulating gas production in low permeability sandstone formations. This paper focuses on laboratory development of a low-damage drilling fluid system by introducing surfactants into the system to prevent waterblocking, combined with optimized temporary bridging agents to reduce the invasion depth of water-based filtrate and film-forming agents to enhance the shale-swelling inhibition of the drilling fluid.

*Corresponding author. email: yanjienian@sina.com Received September 16, 2008

\section{Geological characteristics and potential formation damage}

The target Permian formation in the Sulige gas reservoir is mainly dominated by fine-grained silty sandstone and fine- to medium-grained sandstone. Poor continuity and anisotropic structure are the characteristics of the gas reservoir. The porosity ranges from $6.65 \%$ to $11.04 \%$ and the permeability ranges from $0.32 \times 10^{-3}$ to $1.49 \times 10^{-3} \mu^{2}$. The gas formation has a narrow range of temperature, from 102 to $115^{\circ} \mathrm{C}$, and its average pressure coefficient is 0.87 . In short, the Sulige field can be classified as a low-permeability, high temperature, and low pressure gas reservoir.

The content of clay in target formation is $6.9 \%$, among which the relative contents of illite/smectite, chlorite, kaolinite, and illite are $8.3 \%, 28.2 \%, 13.5 \%$, and $50.0 \%$, respectively. Sensitivity evaluation of cores taken from Well SU10-30-38 (at a depth of 3,840 m) shows moderate water sensitivity and mid-high flow rate sensitivity. Moreover, the low-permeability target formation consists of micro-pores and small fractures. The results of laboratory waterblocking tests show that the damage extent of permeability ranges from $45.1 \%$ to $87.4 \%$. Therefore, the rock may be significantly sensitive to waterblocking, which will decrease gas flow within the tight matrix, and reduce the ultimate productivity of the reservoir. 


\section{Development of new low-damage drilling fluid}

Horizontal drilling is gaining widespread popularity in the Sulige Field because of the advantages horizontal wells offer comparatively to vertical ones. Because of their large contact area with the reservoir, horizontal wells are more susceptible to drilling induced formation damage. Once opened, formations are firstly soaked in drilling fluids. What is the worst, soaking duration will be prolonged due to increasing well depth, circulation loss, drill pipe sticking, and well collapse. Consequently water sensitivity and waterblocking will be easily induced by invading fluids, resulting in a large reduction in effective permeability. Therefore, drilling fluids should have good properties, such as strong inhibition, low filtration, waterblocking prevention, and suitable densities (in near balance/under balance drilling operations), which contribute to avoiding sloughing, lost circulation, pipe sticking, etc. and hence minimizing the formation damage caused by the prolonged soak time.

Based on current drilling fluids technology (Matho and Sharma, 2004; Zhang and Yan, 2004; Pu et al, 2005; Shu and Yan, 2008) and known damage mechanisms (Bennion et al, 2005; Cui and Zhang, 1998; Iscan et al, 2007; Skalli et al, 2006) in low-permeability formations, guidelines for developing the new drilling fluid are described as follows: 1) Selecting formate-based drilling fluid without a solid phase (no clay) and keeping mud density less than $1.05 \mathrm{~g} / \mathrm{cm}^{3}$ in the pay zone known for low formation pressure gradients. 2)
Selecting efficient surfactants to minimize waterblocking. 3) Selecting temporary bridging agents (TBAs) by adopting the technology of Ideal Packing Theory (IPT) to form thinner, tighter mud cake and to achieve good temporary plugging effect. 4) Selecting film-forming agents to enhance the inhibition of the fluid. The final formulation of the drilling fluid should have good rheological properties and good compatibility with the target formation, while satisfying the requirements of a safe density window during drilling operations.

\subsection{Optimization of basic formulation}

Xanthan polymer, modified starch, and oxidized asphalt were introduced as the main additives into sodium formate brine. Their concentrations were determined by the orthogonal experimental method $\left(\mathrm{L9}_{3}{ }^{4}\right)$. A liquid lubricant, $\mathrm{RH}-3$, was selected to provide high lubricity during horizontal drilling operations. Basic formulation (Formulation 1) of the drilling fluid was optimized as below: $5 \%$ sodium formate + $0.4 \%$ xanthan polymer $+1.5 \%$ modified starch $+2 \%$ oxidized asphalt $+10 \%$ liquid lubricant RH-3, and its rheological parameters were measured and shown in Table 1 . The fluid exhibited acceptable drilling properties (viscosity, fluid loss control, etc) before and after exposure to the anticipated bottomhole temperature of $120{ }^{\circ} \mathrm{C}$. Then the film-forming technology and ideal packing theory were used to minimize API fluid loss and HTHP (high temperature and high pressure) fluid loss of the modified drilling fluid.

Table 1 Rheological properties of modified drilling fluids (Formulation 1)

\begin{tabular}{ccccccc}
\hline Experimental conditions & $\begin{array}{c}\text { Density } \\
\rho, \mathrm{g} / \mathrm{cm}^{3}\end{array}$ & $\begin{array}{c}\text { Apparent viscosity } \\
A V, \mathrm{mPa} \cdot \mathrm{s}\end{array}$ & $\begin{array}{c}\text { Plastic viscosity } \\
P V, \mathrm{mPa} \cdot \mathrm{s}\end{array}$ & $\begin{array}{c}\text { Yield point } \\
Y P, \mathrm{~Pa}\end{array}$ & $\begin{array}{c}\text { Gel strength } \\
10^{\prime \prime} / 10^{\prime}, \mathrm{Pa}\end{array}$ & $\begin{array}{c}\text { API filtrate } \\
\mathrm{ml} / 30 \mathrm{~min}\end{array}$ \\
$\begin{array}{c}\mathrm{pH} \text { value } \\
\text { Room temperature }\end{array}$ & 1.05 & 51 & 38 & 13 & $3.0 / 3.0$ & 8.4 \\
After aging at $120^{\circ} \mathrm{C}$ for $16 \mathrm{~h}$ & 1.03 & 34 & 23 & 11 & $1.5 / 1.5$ & 9.7 \\
\hline
\end{tabular}

\subsection{Selection of surfactants}

Capillary pressure, which is the dominant variable controlling fluid retention, is a direct linear function of interfacial tension (IFT) between the water and gas phase. Efficient surfactants can substantially reduce the IFT between the invading water-based filtrate and the in-situ reservoir gas, which reduces the magnitude of the capillary pressure and the degree of waterblocking.

Eight commonly used surfactants were tested at ambient temperature with the drop weight method (Shu and Yan, 2008). The experimental results showed that ABSN, ABS, and OP-10 could significantly reduce IFT between the water and gas phase to $34 \mathrm{mN} / \mathrm{m}$ at the concentration of $0.4 \%$. However, ABS in water solution was apt to produce a large amount of foam after shearing, therefore, ABSN and OP-10 were recommended as additives to prevent the occurrence of waterblocking. ABSN may probably react with $\mathrm{Ca}^{2+}$ to form precipitate when the concentration of $\mathrm{Ca}^{2+}$ is high in formation brine. In this case, OP-10 can be used to replace it. The concentration of both surfactants is recommended as $0.4 \%$.
Recently, a new surfactant, HAR has proved to be a better waterblocking prevention agent. Its capability to reduce IFT was confirmed through measuring surface tension of its aqueous solution (Fig. 1). The surface tension of $2 \%$ aqueous solution was $20 \mathrm{mN} / \mathrm{m}$. Considering surfactant absorption by drilling solids, the concentration of HAR is recommended as $0.4 \%$.

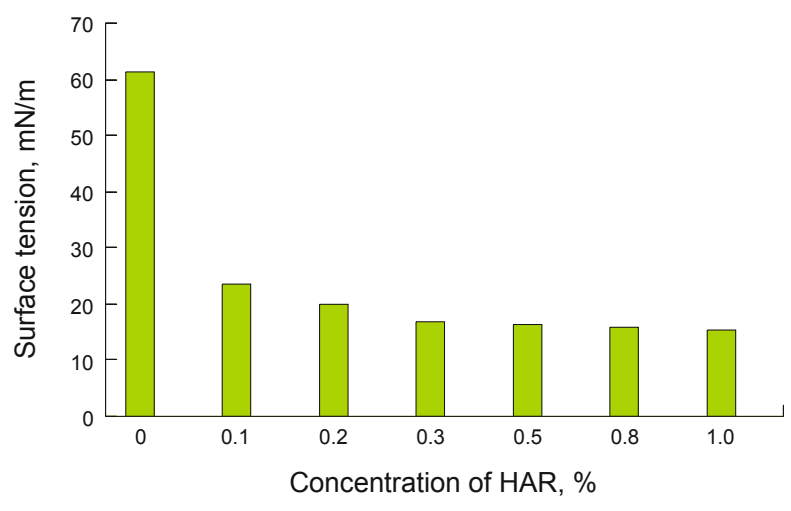

Fig. 1 Capability of HAR to reduce surface tension 


\subsection{Selection of film-forming agents}

Ultra-low invasion drilling fluids take advantage of specific polymers that are strongly adsorbed onto the borehole interface where numerous deformable polymer micelles are developed and associated to form a tight, ultralow permeability film, thus preventing fluid loss from pore throat invasion with wide-ranging size distribution or microfractures. The object of controlling the filtrate to near-zero will be achieved consequently.

Ultra-low permeability film-forming agents are one of the key factors of film-forming technology. FLC2000 and CMJ-2, two types of widely used film-forming agents, were selected and used for laboratory optimization experiments. They are mainly composed of plant-derivatives, water-soluble or partly water-soluble synthetic organic polymers and metal oxides, which are environmentally friendly and have good hightemperature stability.

\subsubsection{Impact of film-forming agents on drilling fluid properties}

The drilling fluid (Formulation 1) was treated with filmforming agents and aged for 24 hours, then agitated by rolling at $120^{\circ} \mathrm{C}$ for 16 hours. The fluid properties before and after hot rolling were measured, as shown in Table 2, which indicated that lower fluid loss could be achieved after adding film-forming agent into the drilling fluid. Moreover, the two products had little impact on rheological parameters of the drilling fluid and exhibited good temperature stability.

Table 2 Impact of film-forming agents on drilling fluid properties

\begin{tabular}{ccccccc}
\hline Test No. & Chemical types & $\begin{array}{c}\text { Apparent viscosity } \\
A V, \mathrm{mPa} \cdot \mathrm{s}\end{array}$ & $\begin{array}{c}\text { Plastic viscosity } \\
P V, \mathrm{mPa} \cdot \mathrm{s}\end{array}$ & $\begin{array}{c}\text { Gels } \\
\text { 10sec/10min } \\
\mathrm{Pa}\end{array}$ & $\begin{array}{c}\text { API filtrate } \\
\mathrm{ml} / 30 \mathrm{~min}\end{array}$ & $\begin{array}{c}\text { HTHP filtrate } \\
\mathrm{ml} / 30 \mathrm{~min}\end{array}$ \\
\hline 1 & Formulation 1 & 51 & 38 & $3.0 / 3.0$ & 8.4 & 23.0 \\
2 & $1+2 \% \mathrm{CMJ}-2$ & 56 & 43 & $4.2 / 6.0$ & 6.0 & 11.0 \\
3 & $2 / 120^{\circ} \mathrm{C}, 16 \mathrm{~h}$ & 40 & 27 & $4.0 / 7.0$ & 6.5 & 13.0 \\
4 & $1+2 \% \mathrm{FLC} 2000$ & 54 & 41 & $4.0 / 5.5$ & 5.7 & 10.0 \\
5 & $4 / 120^{\circ} \mathrm{C}, 16 \mathrm{~h}$ & 53 & 43 & $3.5 / 6.0$ & 6.1 & 11.2 \\
\hline
\end{tabular}

\subsubsection{Dynamic filtration test}

CMJ-2 and FLC2000 were tested as potential fluidloss-control agents using stainless steel cores, which were developed to simulate fractures with different sizes (Ye et al, 2008). The simulated cores were split into two parts and could be easily assembled by a slipping operation. Then, the invasion depth of drilling fluids could be observed directly.

After the simulated cores with a fracture width of $50 \mu \mathrm{m}$ were mounted in a core holder of the HPHT filtration tester, dynamic filtration of drilling fluids was performed at 90 ${ }^{\circ} \mathrm{C}$ and experimental results are listed in Table 3 . The spurt loss, total loss and invasion depth reduced significantly after adding each film-forming agent. Considering material cost and supply source, CMJ-2 is recommended as a film-forming agent to improve fluid performance and its concentration is recommended as $2 \%$.

Table 3 Data for the dynamic filtration tests

\begin{tabular}{ccccc}
\hline Test No. & $\begin{array}{c}\text { Type of drilling } \\
\text { fluid }\end{array}$ & $\begin{array}{c}\text { Spurt loss } \\
\mathrm{ml}\end{array}$ & $\begin{array}{c}\text { Total loss } \\
\mathrm{ml}\end{array}$ & $\begin{array}{c}\text { Invasion depth } \\
\mathrm{cm}\end{array}$ \\
\hline 1 & Formulation 1 & 6.2 & 18.5 & 3.3 \\
2 & $1+1 \%$ CMJ-2 & 3.5 & 12.0 & 2.5 \\
3 & $1+1 \%$ FLC2000 & 3.2 & 10.6 & 2.2 \\
4 & $1+2 \%$ CMJ-2 & 1.8 & 7.5 & 0.8 \\
5 & $1+2 \%$ FLC2000 & 1.5 & 6.4 & 0.6 \\
\hline
\end{tabular}

\subsection{Optimization of temporary bridging agents}

The Ideal Packing Theory (IPT) takes a graphical approach to determine the optimum particle-size distribution of bridging material for given formation characteristics (Dick et al, 2000). Based on the relationship between the particle size distribution (PSD) of the temporary bridging agent (TBA) and pore throat size distribution, $d_{90}$ ( $90 \%$ of the particles are smaller than the size) of TBA was determined by adopting $d_{90}$ rule (Hands et al, 1998), and corresponding matching smart software (Zhang and Yan, 2004). Considering shearing and abrasion of TBA in the annulus between the drillstring and the well borehole, finally optimized TBA (a combination of different calcium carbonate particle sizes) was determined as below: $45 \mu \mathrm{m}(30 \%), 23 \mu \mathrm{m}(50 \%)$ and $13 \mu \mathrm{m}(20 \%)$.

Rheological parameters and dynamic fluid loss of drilling fluids were measured after adding optimized TBA (shown in Table 4 and Fig. 2). TBA had little impact on rheological parameters and fluid loss was further reduced. The total loss decreased from 18.5 to $6.3 \mathrm{ml}$, while spurt loss (instantaneous loss) decreased significantly, indicating that the bridging agents, TBAs, result in a tighter and less invading filter cake. The concentration of optimized TBA in drilling fluids is recommended as $4 \%$.

Based on the above optimization results, the new lowdamage drilling fluid system (Formulation 2) has been developed. Its typical formulation is shown in Table 5. 
Table 4 Optimized TBA and its impact on the properties of drilling fluids

\begin{tabular}{|c|c|c|c|c|c|c|c|}
\hline \multicolumn{2}{|c|}{ Fluid properties } & $\begin{array}{c}\rho \\
\mathrm{g} / \mathrm{cm}_{3}\end{array}$ & $\begin{array}{c}A V / P V \\
\mathrm{mPa} \cdot \mathrm{s}\end{array}$ & $\begin{array}{l}Y P \\
\mathrm{~Pa}\end{array}$ & $\begin{array}{c}\text { Gels } \\
10 \mathrm{sec} / 10 \mathrm{~min} \\
\mathrm{~Pa}\end{array}$ & $\begin{array}{l}\text { API filtrate } \\
\mathrm{ml} / 30 \mathrm{~min}\end{array}$ & $\mathrm{pH}$ value \\
\hline \multirow{2}{*}{ Formulation 1} & Room temperature & 1.05 & $51 / 38$ & 13.0 & $3.0 / 3.0$ & 8.4 & 10 \\
\hline & $120^{\circ} \mathrm{C} / 16 \mathrm{~h}$ & 1.03 & $34 / 23$ & 11.0 & $1.5 / 1.5$ & 9.7 & 9 \\
\hline \multirow{2}{*}{$1+3 \%$ TBA } & Room temperature & 1.05 & $53 / 41$ & 12.0 & $3.0 / 3.0$ & 7.0 & 10 \\
\hline & $120^{\circ} \mathrm{C} / 16 \mathrm{~h}$ & 1.03 & $35 / 24$ & 11.0 & $1.5 / 1.5$ & 8.2 & 9 \\
\hline \multirow{2}{*}{$1+4 \%$ TBA } & Room temperature & 1.05 & $54 / 44$ & 10.0 & $3.0 / 3.5$ & 6.3 & 10 \\
\hline & $120^{\circ} \mathrm{C} / 16 \mathrm{~h}$ & 1.04 & $35.5 / 25$ & 10.5 & $1.5 / 1.5$ & 6.9 & 9 \\
\hline \multirow{2}{*}{$1+5 \%$ TBA } & Room temperature & 1.05 & $54 / 45$ & 9.0 & $3.0 / 3.0$ & 5.5 & 10 \\
\hline & $120^{\circ} \mathrm{C} / 16 \mathrm{~h}$ & 1.04 & $37 / 29$ & 8.0 & $1.5 / 2.0$ & 6.0 & 9 \\
\hline
\end{tabular}

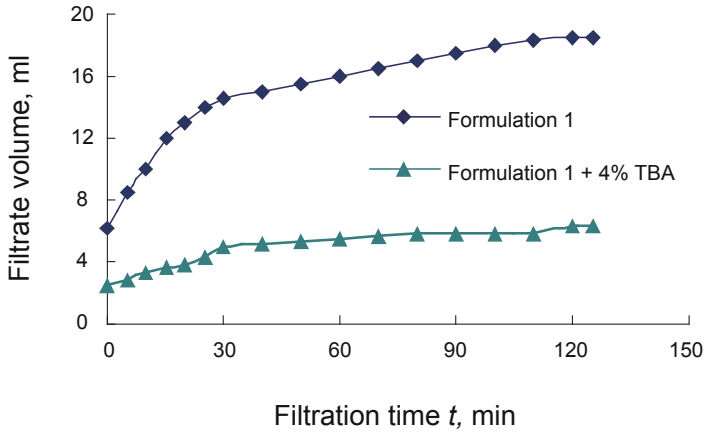

Fig. 2 Dynamic loss of drilling fluids with or without optimized TBAs

Table 5 Typical formulation of the new low-damage drilling fluid

\begin{tabular}{cc}
\hline Product & Concentration, $\mathrm{kg} / \mathrm{m}^{3}$ \\
\hline Sodium formate & 50 \\
Xanthan polymer & 4 \\
Modified starch & 15 \\
Oxidized asphalt & 20 \\
Liquid lubricant RH-3 & 100 \\
HAR & 4 \\
CMJ-2 & 20 \\
Optimized TBA & 40 \\
\hline
\end{tabular}

\section{Comprehensive evaluation of the new low- damage drilling fluid}

\subsection{Conventional evaluation of fluid properties}

The new low-damage drilling fluid was tested in the laboratory. Table 6 shows the experimental results which are reasonable indicators that the new drilling fluid has good performance at room or higher temperatures. What is of importance, with its friction coefficient less than 0.1 and yield point in excess of $10 \mathrm{~Pa}$, the fluid can provide steel/steel and steel/rock lubricity and excellent hole cleaning and cuttings suspension. Consequently, it can meet the requirements of horizontal drilling in low-permeability gas formations.

\subsection{Compatibility with target formation}

A cuttings recovery test was performed by using 6-10 mesh $(2-3.5 \mathrm{~mm})$ rock cuttings from the medium-grained sandstone of the Permian formation of Sulige reservoir. The cuttings were rolled in the new drilling fluid at $120^{\circ} \mathrm{C}$ for 16 hours and the weight of cuttings recovered on a 40-mesh sieve $(2 \mathrm{~mm})$ was then calculated. Over $99 \%$ recovery was obtained, while the shape and size of rock cuttings had not obviously changed, illustrating that the new drilling fluid has good compatibility with formation rock. Furthermore, mixing the mud filtrate with simulated formation brine in different proportions resulted in no flocculation, precipitation, and other chemical reactions, indicating better compatibility with formation brine.

Table 6 Parameters of the low-damage drilling fluid

\begin{tabular}{ccccccccc}
\hline $\begin{array}{c}\rho \\
\mathrm{g} / \mathrm{cm}^{3}\end{array}$ & $\begin{array}{c}A V \\
\mathrm{mPa} \cdot \mathrm{s}\end{array}$ & $\begin{array}{c}P V \\
\mathrm{mPa} \cdot \mathrm{s}\end{array}$ & $\begin{array}{c}Y P \\
\mathrm{~Pa}\end{array}$ & $\begin{array}{c}\mathrm{Gels} \\
10 \mathrm{sec} / 10 \mathrm{~min} \\
\mathrm{~Pa}\end{array}$ & $\begin{array}{c}\text { API } \\
\text { filtrate } \\
\mathrm{ml} / 30 \mathrm{~min}\end{array}$ & $\begin{array}{c}\text { HTHP } \\
\text { filtrate } \\
\mathrm{ml} / 30 \mathrm{~min}\end{array}$ & $\begin{array}{c}\text { Friction coefficient } \\
K_{f}\end{array}$ & $\begin{array}{c}\text { Experimental } \\
\text { conditions }\end{array}$ \\
\hline 1.05 & 59 & 47 & 12.0 & $3.5 / 4.0$ & 5.4 & 12.5 & 0.091 & Room temperature \\
1.04 & 45 & 34 & 11.0 & $2.0 / 3.0$ & 7.1 & 14.2 & 0.066 \\
\hline
\end{tabular}




\subsection{Dynamic formation damage test}

The new low-damage drilling fluids were submitted to dynamic formation damage test on core samples taken from low-permeability target formation in Well SU10-3038 (at a depth of $3,840 \mathrm{~m}$ ). The test was performed on the JHMF-2 dynamic damage experimental apparatus. With this apparatus, overburden stress and temperature could be controlled to simulate in-situ reservoir conditions. A flow system provided the means to circulate drilling fluids.
The following test conditions were applied during testing: temperature $90{ }^{\circ} \mathrm{C}$, differential pressure $3.5 \mathrm{MPa}$, and shear rate $150 \mathrm{~s}^{-1}$. Table 7 indicated that return permeability reached $86.9 \%$ and $83.6 \%$, respectively. During the test, dynamic fluid loss of the new drilling fluid was measured, as shown in Fig. 3. Compared with Formulation 1, the new fluid had lower spurt loss and total fluid loss. The object of reducing formation damage and minimizing fluid invasion was achieved.

Table 7 Dynamic damage of the new low-damage drilling fluid

\begin{tabular}{ccccc}
\hline $\begin{array}{c}\text { Core } \\
\text { No. }\end{array}$ & $\begin{array}{c}\text { Gas permeability } \\
K_{\mathrm{a}}, 10^{-3} \mu \mathrm{m}^{2}\end{array}$ & $\begin{array}{c}\text { Oil permeability before damage } \\
K_{\mathrm{o} 1}, 10^{-3} \mu \mathrm{m}^{2}\end{array}$ & $\begin{array}{c}\text { Oil permeability after damage } \\
K_{\mathrm{o} 2}, 10^{-3} \mu \mathrm{m}^{2}\end{array}$ & $\begin{array}{c}\text { Return permeability } \\
K_{\mathrm{o} 2} / K_{\mathrm{o} 1}, \%\end{array}$ \\
\hline SU-1 & 8.60 & 1.45 & 1.26 & 86.9 \\
SU-2 & 6.75 & 1.34 & 1.12 & 83.6 \\
\hline
\end{tabular}

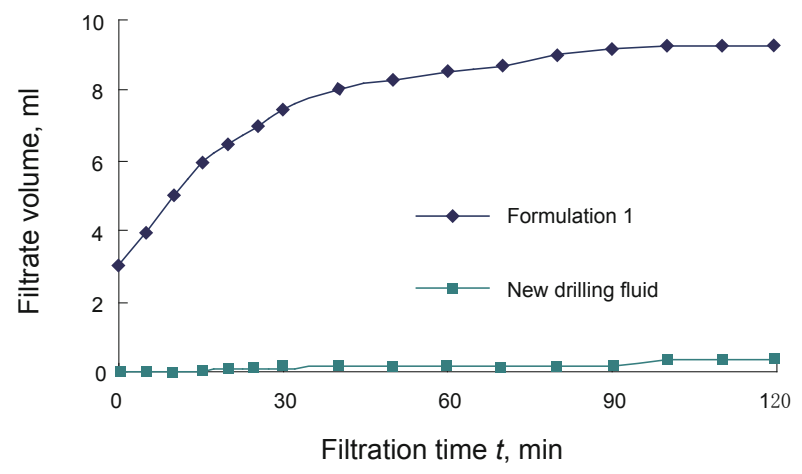

Fig. 3 Dynamic damage curves of low-damage drilling fluids

\subsection{Waterblocking test}

In the waterblocking test (Bennion et al, 2000a), core samples from the coarse-grained sandstone of the lowpermeability Permian formation in Well SU10-30-38 (4,056 $\mathrm{m}$ true depth (TD)) were used. The samples were restored to proper initial saturation. A baseline series of permeability measurements was conducted over the range of 0-2 $\mathrm{MPa}$. This was followed by invasion of the sample with a specified volume of drilling fluid filtrate. This procedure was then followed by a series of permeability regain measurements, conducted at the same drawdown levels as the baseline preexposure permeabilities. Figs. 4 and 5 indicated that the new fluid could significantly minimize waterblocking effects. The permeability reduction induced by new fluid filtrate invasion was $23.6 \%$, while the value induced by the drilling fluid without surfactants (Formation 1) was as high as $72.5 \%$.

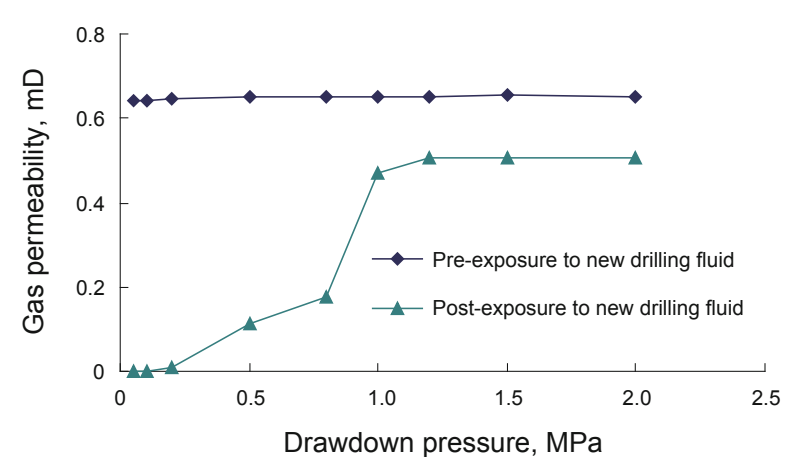

Fig. 4 Gas permeability data from waterblocking test using the new drilling fluid

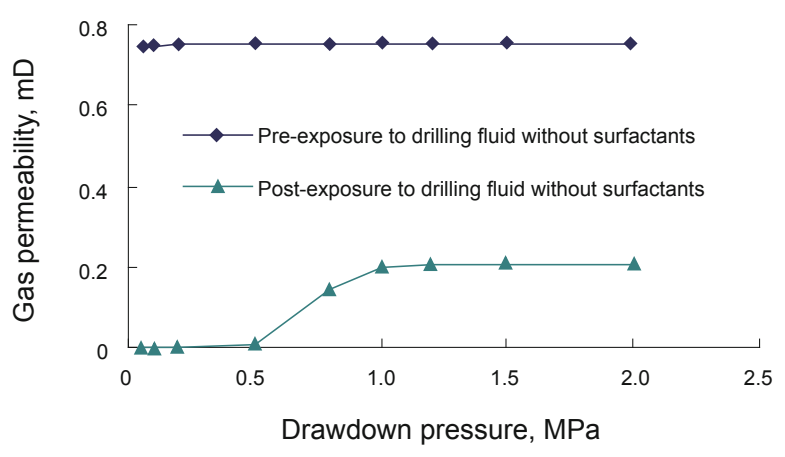

Fig. 5 Gas permeability data from waterblocking test using Formulation 1 without surfactant

\section{Application of the new drilling fluid}

The new drilling fluid was used on Well SU10-30-38H, the first horizontal well drilled in SU10 block, the north of 
the Ordos Basin. The drillers circulated the surface hole section (0-502 m TD) with clay-based drilling fluid. Then, the vertical section (502-2,600 m TD) was drilled with polymer drilling fluid. After drilling this section, a dispersion system containing xanthan polymer and sulfonated polymers was used to drill through the kick off section (2,600-3,453 m TD). Once in the reservoir section $(3,453-4,088 \mathrm{~m}$ TD), the operator flushed the circulation system and began drilling with the engineered formate-based drilling fluid. Due to the absence of a solid phase, aided by effective lubricating properties, the fluid performed very well in the horizontal section as long as $638.32 \mathrm{~m} .71 \%$ of the gas producing formations existing in the horizontal section was drilled open. Well test engineers found that this fluid did not negatively affect the reservoir. The average skin factor along the horizontal well length was -2.63 . Compared with an offset well, higher flowback rate and shorter clean-up time than were observed, an evidence of minimal water blocking caused by fluid invasion.

\section{Conclusions}

1) Waterblocking is a special case of the relative permeability problems that often plague the success of lowpermeability gas reservoir production operations. Water can cause blocking in the low-pressure, low-permeability formations of Sulige gas reservoir.

2) Fluid retention is controlled by capillary pressure, which is a linear function of interfacial tension (IFT) between the water and gas phases. Drilling fluid containing surfactants to reduce IFT between the water-based filtrate and in-situ reservoir gas, contributes to mitigation of waterblocking in low-permeability gas reservoirs.

3) The formate-based drilling fluid, which is composed of optimized TBA, film-forming agents, and waterblocking prevention surfactants, can efficiently minimize waterblocking. It has good compatibility with the target formation, high return permeability, low density, low fluid loss, small friction coefficient, and satisfactory rheological parameters, favorable to horizontal well drilling in low permeability and low pressure gas reservoir of the Sulige Field.

\section{Acknowledgements}

The authors thank the Committee of the National High Technology Research and Development Program of China (863 Program) for providing financial support for this research project (Project No. 2006AA06A109). We also appreciate the support provided by the Changjiang Scholars and Innovative Research Team (No. IRT0411), Ministry of Education, China.

\section{References}

Bennion D B and Thomas F B. Formation damage issues impacting the productivity of low permeability, low initial water saturation gas producing formations. Journal of Energy Resources Technology. 2005. 127(3): 240-247

Bennion D B, Thomas F B, Bietz R F, et al. Remediation of water and hydrocarbon phase trapping problems in low permeability gas reservoirs. Journal of Canadian Petroleum Technology. 1999. 38(8): $39-48$

Bennion D B, Thomas F B and Ma T. Recent advances in laboratory test protocols for evaluating optimum drilling, completion and stimulation practices the low permeability gas reservoirs. SPE Rocky Mountain Regional/Low Permeability Reservoirs Symposium and Exhibition held in Denver, Colorado, 12-15 March, 2000a (SPE paper 60324)

Bennion D B, Thomas F B and Ma T. Formation damage processes reducing productivity of low permeability gas reservoirs. SPE Rocky Mountain Regional/Low Permeability Reservoirs Symposium and Exhibition held in Denver, Colorado, 12-15 March, 2000b (SPE paper 60325)

Cui Y C and Zhang Y. Characteristics of formation damage in low permeability reservoirs. Drilling Fluid and Completion Fluid. 1998. 15(2):11-13 (in Chinese)

Dick M A, Heinz T J and Svoboda C F. Optimizing the selection of bridging particles for reservoir drilling fluids. SPE International Symposium on Formation Damage held in Lafayette, Louisiana, 2324 February, 2000 (SPE paper 58793)

Erwom M D, Riersom C R, and Bennion D B. Brine imbibition damage in the Colville River Field. SPE Annual Technical Conference and Exhibition held in Denver, Colorado, 5-8 October, 2003 (SPE paper 84320)

Hands N, Kowbel K, Maikranz S, et al. Drill-in fluid reduces formation damage, increases production rates. Oil \& Gas Journal. 1998. 96(28): 68-69

Iscan A G, Civan F and Mustafa V K. Alteration of permeability by drilling fluid invasion and flow reversal. Journal of Petroleum Science and Engineering. 2007. 58(1-2): 227-244

Lin G R, Shao C G, Xu Z F, et al. Fluid damage and solution method study of low permeability gas reservoirs. Petroleum Exploration and Development. 2003. 30(6): 117-118 (in Chinese)

Mahto V and Sharma V P. Rheological study of a water based oil well drilling fluid. Journal of Petroleum Science and Engineering. 2004. 45(1-2): $123-128$

Pu X L, Lei G, Luo X S, et al. Study of membrane theory and filmforming drilling fluid. Drilling Fluid and Completion Fluid. 2005. 22(6): 1-4 (in Chinese)

Ren X J, Zhang N S, Zhang X F, et al. Damage of residual water on permeability of tight gas reservoir. Natural Gas Industry. 2004. 24(11): 106-108 (in Chinese)

Shu Y and Yan J N. New fluids prevent formation damage to Tarim sandstones. Oil \& Gas Journal. 2008. 106(19): 45-49

Skalli L, Buckley J S, Zhang Y, et al. Surface and core wetting effects of surfactants in oil-based drilling fluids. Journal of Petroleum Science and Engineering. 2006. 52(1-4): 253-260

Ye Y, Yan J N, Zou S L, et al. A new laboratory method for evaluating formation damage in fractured carbonate reservoirs. Petroleum Science. 2008. 5(1): 45-51

Zhang J B and Yan J N. New theory and method for optimizing the particle size distribution of bridging agents in drilling fluids. Acta Petrolei Sinica. 2004. 25(6): 88-91(in Chinese)

(Edited by Sun Yanhua) 